\title{
0329. Beneficial effects of azithromycin combined with ceftazidime without activity against P. aeruginosa in a murine sepsis model of peritonitis by Pseudomonas aeruginosa
}

\author{
ME Pachón-Ibañez ${ }^{1}$, A Díaz-Martín²* , J Dominguez-Herrera' ${ }^{1}$, G Labrador ${ }^{1}$, Y Smani ${ }^{1}$, J Pachón ${ }^{1}$, \\ J Garnacho-Montero²
}

From ESICM LIVES 2014

Barcelona, Spain. 27 September - 1 October 2014

\section{Introduction}

Despite a proper management, the mortality of patients with severe sepsis and septic shock is very high. During sepsis, an uncontrolled cascade of inflammatory mediators is triggered, leading to tissue damage that can cause death. Macrolides, apart from their antibiotic properties, are capable of modulating inflammatory response. Macrolides inhibit the production and secretion of pro-inflammatory cytokines (IL-1, IL-6, IL-8 and TNF- $\alpha$ ) levels and increase anti-inflammatory cytokines such as IL-10.

\section{Objectives}

To demonstrate whether the use of azithromycin (AZM) in a murine sepsis model of $P$. aeruginosa increases ceftazidime (CFZ) efficacy.

\section{Methods}

$\mathrm{MIC} / \mathrm{MBC}$ and bactericidal activity (time-killed curves using $1 \mathrm{MIC}$ ) were performed using four clinical isolates of $P$. aeruginosa. The bactericidal activity on $\mathrm{Pa} 4$, chosen for the in vivo study, was carried out too at the maximum plasma concentration (Cmax) in mice. Pharmacokinetic/pharmacodynamic (PK/PD) parameters of CFZ and AZM were calculated (HPLC-MS/MS). The activity of each antimicrobial agent and its combination was assessed in a murine peritonitis model $(n=15)$, using the minimum lethal dose (MLD) of Pa4 as inoculum. Treatment were: $100 \mathrm{mg} / \mathrm{kg} / \mathrm{ip} / 12 \mathrm{~h}$ for CFZ and $30 \mathrm{mg} /$ $\mathrm{kg} / \mathrm{ip} / 24 \mathrm{~h}$ for AZM, during 72 hours; a group of 15

${ }^{2}$ University Hospital Virgen del Rocio, Intensive Care Unit, Seville, Spain Full list of author information is available at the end of the article untreated mice were used as control (CON). CFU/g spleen, mortality and blood cultures were compared.

\section{Results}

The MIC/MBC (mg/L) ranges of CFZ were 2-4/2-32 and for AZM 64/128->128. In time-kill curves no bactericidal activity was observed with any of the strains at concentration of $1 \mathrm{MIC}$. At concentration of Cmax, CFZ + AZM reached bactericidal activity, but not synergy was found. PK/PD results are shown in table 1 . In the animal model (table 2), CFZ and CFZ+AZM were better than $C O N$ and $A Z M$, and the combination better than the CFZ and AZM ( $p<0.001$, ANOVA, post hoc tests) respect to the CFU/g spleen and the blood cultures. No differences were found in the mortality rates (chi-square test). In the survival analysis, CFZ+AZM delayed the mortality compared with the other groups $(\mathrm{p}<0.001$, Kaplan-Meier).

Table 1 PK/PD results

\begin{tabular}{cccc}
\hline & & CFZ & AZM \\
\hline PK & Cmax $(\boldsymbol{\mu g} / \mathbf{m L})$ & 107.14 & 4.57 \\
\hline PK & Tmax $(\mathbf{h})$ & 1.08 & 2.14 \\
\hline PK & AUC0- $\infty\left(\boldsymbol{\mu g}{ }^{*} \mathbf{h} / \mathbf{L}\right)$ & 126.83 & 3.81 \\
\hline PD & Cmax/MIC & 107.14 & 0.07 \\
\hline PD & T1/2/MIC & 1.08 & 0.02 \\
\hline PD & AUC0- $\infty / M I C$ & 126.83 & 1.98 \\
\hline
\end{tabular}


Table 2 In vivo studies

\begin{tabular}{|c|c|c|c|c|}
\hline & CON & CFZ & AZM & $\begin{array}{r}\text { CFZ } \\
+ \text { AZM } \\
\end{array}$ \\
\hline $\begin{array}{c}\text { Log UFC/g Spleen (Mean } \\
\pm \text { SD) }\end{array}$ & $\begin{array}{c}8.40 \pm \\
0.32 \\
\end{array}$ & $\begin{array}{c}6.57 \pm \\
0.61 \\
\end{array}$ & $\begin{array}{c}7.58 \pm \\
0.31 \\
\end{array}$ & $\begin{array}{c}4.63 \pm \\
0.77 \\
\end{array}$ \\
\hline Positive blood culture (\%) & 100 & 47 & 100 & 0 \\
\hline Exitus (\%) & 100 & 100 & 100 & 100 \\
\hline
\end{tabular}

\section{Conclusions}

The combination of AZM with CFZ increases bacterial clearance from spleen and blood and delays the time to mortality in a murine sepsis model by $P$. aeruginosa.

\section{Grant acknowledgment}

This project (PI10/01563) was funded by the "Fondo de Investigación

Sanitaria", Instituto de Salud Carlos III.

\section{Authors' details}

${ }^{1}$ UCEIMP/IBIS-University Hospital Virgen del Rocío, University of Seville, Seville, Spain. ${ }^{2}$ University Hospital Virgen del Rocio, Intensive Care Unit, Seville, Spain.

Published: 26 September 2014

doi:10.1186/2197-425X-2-S1-P18

Cite this article as: Pachón-lbañez et al:: 0329. Beneficial effects of azithromycin combined with ceftazidime without activity against $P$. aeruginosa in a murine sepsis model of peritonitis by Pseudomonas aeruginosa. Intensive Care Medicine Experimental 2014 2(Suppl 1):P18.

\section{Submit your manuscript to a SpringerOpen ${ }^{\mathcal{O}}$ journal and benefit from:}

- Convenient online submission

- Rigorous peer review

- Immediate publication on acceptance

- Open access: articles freely available online

- High visibility within the field

- Retaining the copyright to your article 